\title{
IgG responses to the gSG6-P1 salivary peptide for evaluating human exposure to Anopheles bites in urban areas of Dakar region, Sénégal
}

Papa M Drame ${ }^{1 *}$, Vanessa Machault ${ }^{2,3,4}$, Abdoulaye Diallo ${ }^{5}$, Sylvie Cornélie ${ }^{1}$, Anne Poinsignon ${ }^{1}$, Richard Lalou ${ }^{6}$, Mbacké Sembène ${ }^{7}$, Stéphanie Dos Santos ${ }^{8}$, Christophe Rogier ${ }^{2,9}$, Frédéric Pagès ${ }^{2}$, Jean-Yves Le Hesran ${ }^{5}$ and Franck Remoué ${ }^{10}$

\begin{abstract}
Background: Urban malaria can be a serious public health problem in Africa. Human-landing catches of mosquitoes, a standard entomological method to assess human exposure to malaria vector bites, can lack sensitivity in areas where exposure is low. A simple and highly sensitive tool could be a complementary indicator for evaluating malaria exposure in such epidemiological contexts. The human antibody response to the specific Anopheles gSG6-P1 salivary peptide have been described as an adequate tool biomarker for a reliable assessment of human exposure level to Anopheles bites. The aim of this study was to use this biomarker to evaluate the human exposure to Anopheles mosquito bites in urban settings of Dakar (Senegal), one of the largest cities in West Africa, where Anopheles biting rates and malaria transmission are supposed to be low.
\end{abstract}

Methods: One cross-sectional study concerning 1,010 (505 households) children ( $n=505)$ and adults $(n=505)$ living in 16 districts of downtown Dakar and its suburbs was performed from October to December 2008. The IgG responses to gSG6-P1 peptide have been assessed and compared to entomological data obtained in or near the same district.

Results: Considerable individual variations in anti-gSG6-P1 lgG levels were observed between and within districts. In spite of this individual heterogeneity, the median level of specific $\lg G$ and the percentage of immune responders differed significantly between districts. A positive and significant association was observed between the exposure levels to Anopheles gambiae bites, estimated by classical entomological methods, and the median IgG levels or the percentage of immune responders measuring the contact between human populations and Anopheles mosquitoes. Interestingly, immunological parameters seemed to better discriminate the exposure level to Anopheles bites between different exposure groups of districts.

Conclusions: Specific human IgG responses to gSG6-P1 peptide biomarker represent, at the population and individual levels, a credible new alternative tool to assess accurately the heterogeneity of exposure level to Anopheles bites and malaria risk in low urban transmission areas. The development of such biomarker tool would be particularly relevant for mapping and monitoring malaria risk and for measuring the efficiency of vector control strategies in these specific settings.

\footnotetext{
* Correspondence: papa-makhtar.drame@ird.fr

'Unité Mixte de Recherche MIVEGEC (IRD 224-CNRS 5290-UM1), Institut de

Recherche pour le Développement, 34394, Montpellier Cedex 8, France

Full list of author information is available at the end of the article
} 


\section{Background}

Currently, almost one billion people live in unstable or extremely low malaria risk areas, corresponding mainly to seasonal transmission, highlands $(>1,500 \mathrm{~m})$, arid/ semi-arid and urban areas [1]. In the latter, malaria can be a serious public health problem, especially in several rapid growing African cities where migrations of human populations from the countryside is intensive [2-4]. While urban development was generally believed to reduce the risk of malaria vector breeding, and thus malaria transmission, many African countries have declining economies, and most of them are struggling to cope with the pace and the extent of urbanization in their cities [2,5]. This may favour malaria vectors' breeding sites [6] and local malaria transmission [7]. In addition, people living in urban regions could be, in spite of their low exposure level to Anopheles vector bites, at a high risk of malarial morbidity and mortality, because of their delayed acquisition or lack of protective immunity [7]. The epidemiology of malaria in cities appeared therefore accurate, and urban malaria has been considered to be a major emerging problem of public health in Africa [8].

Dakar area is a typical example of sub-Saharan Africa's sprawling cities where malaria risk and transmission has been studied for several years. Malaria pathogens are transmitted by species of Anopheles gambiae complex (namely An. gambiae s. l.). Anopheles arabiensis is the most abundant Anopheles vector species and transmits mainly Plasmodium falciparum [9-12]. Anopheles melas, secondarily associated to $P$. falciparum transmission and An. gambiae s. s. M form have been described in low densities [10]. Malaria risk in Dakar is very focal, due to a high diversity in the degree and type of urbanization, the variation of density of human populations, the quality of water and waste management, the differential nature and use of vector control strategies and other own household factors [13]. A recent study has underlined possible changes in human exposure level to Anopheles bites in Dakar area. Indeed, due to an important increase of the building developments, estimated about $30 \%$ of the total area, the population at high risk for malaria fell from $32 \%$ to $20 \%$, whereas the low risk population rose from 29 to $41 \%$ between 1996 and 2007 [14]. These findings suggest a current need to evaluate accurately the malaria risk in Dakar settings.

The evaluation of malaria risk using classical entomological methods presents considerable limitations in urban settings. Heavy sampling efforts are required to assess exposure level to Anopheles bites and then to evaluate the risk of malaria by entomological tools (trappings, human-landing catches, residual sprayings, etc.), especially in low urban exposure [15-17]. In addition, such methods are mainly applicable at population level and do not allow the evaluation of the heterogeneity of exposure between individuals. Moreover, these methods are not adapted to consider differential attractiveness to mosquitoes between individuals or other environmental and socio-economic factors, which could induce important variations in individual exposure to vector bites [17]. Such factors could be all the more considerable in urban areas. A simple, specific and highly sensitive indicator is therefore needed to evaluate the human exposure levels to Anopheles bites and potentially the risk of malaria in urban areas, at individual and population levels [18].

The measurement of antibody $(\mathrm{Ab})$ response to vector saliva in human populations has been described to be a pertinent tool to assess the host exposure level to vector bites and the risk of vector-borne disease $[19,20]$. Salivary proteins of haematophagous arthropods facilitate blood feeding by counteracting haemostatic and inflammatory reactions and by modulating the immune response of the human or animal host [21,22]. Some of them can also induce a specific Ab response [23] which could represent a reliable indicator of vertebrate host exposure to vector-borne diseases in individuals bitten by arthropod vectors, such as ticks [24], sand-flies [25], Triatoma [26], Glossina [27], Aedes [28,29], Culex [30], An. gambiae [31,32], Anopheles dirus [33] and Anopheles darlingi [34]. But, the use of whole saliva could not give a pertinent biomarker, because of i) the potential crossreactivity with salivary epitopes of other haematophagous arthropods; ii) the lack of reproducibility between saliva batches, and iii) an inadequate production needed for large-scale studies [35,36]. For these purposes, a specific, antigenic, easy synthesized and highly conserved peptide between Anopheles mosquitoes, the gSG6-P1 (An. gambiae Salivary Gland Protein-6 peptide 1), has been identified and validated as a more pertinent biomarker of Anopheles bites [36]. Indeed, specific IgG responses to this gSG6-P1 peptide seemed to give an accurate evaluation of low and very low-level exposure to An. gambiae [18] as well as to Anopheles funestus bites, the second major malaria vector in Africa [37]. Recently, it has been also shown that Ab response to gSG6-P1 peptide offers a useful biomarker for a reliable assessment of the efficacy of impregnated bed-net use against exposure to Anopheles bites [35]. In addition, specific IgG response to gSG6-P1 does not seem to build up but wanes rapidly, when exposure failed. This property represents a major strength for its use for evaluating the human exposure to mosquito bites in lowexposure contexts [35].

The aim of the present study was to evaluate the exposure level to malaria vectors in individuals living in a supposed low endemic urban area (Dakar) by using 
specific human IgG responses to the Anopheles gSG6-P1 salivary peptide biomarker.

\section{Methods \\ Study site}

The region of Dakar (the capital city of Senegal) is located in the Cape Verde Peninsula (14. 43' 29.06" North, $17^{\circ} 28^{\prime} 24.06^{\prime \prime}$ West) at the western point of Africa. In 2008, Dakar population was estimated to $2,500,000$ inhabitants, amounting to $21 \%$ of the total population of the country (about 12,000,000 inhabitants), with a high population density (4,459 inhabitants $/ \mathrm{km}^{2}$ ). Globally, the studied region is a coastal plain area and has a mild sahelian climate with a hot and wet season which lasts from June to November and is characterized by average temperatures between 24 and $30^{\circ} \mathrm{C}$. In 2008, the annual average rainfall was $510 \mathrm{~mm}$ and peaked in August and September [38]. The study was conducted in 2008, from the end of the rainy season (October) to the beginning of the dry season (December), in different areas of downtown Dakar (Dakar department) and suburbs (Pikine and Guediawaye departments) (Figure 1). Plasmodium species (mainly $P$. falciparum) are transmitted by An. gambiae s.l. mosquitoes (mainly An. arabiensis) and malaria transmission

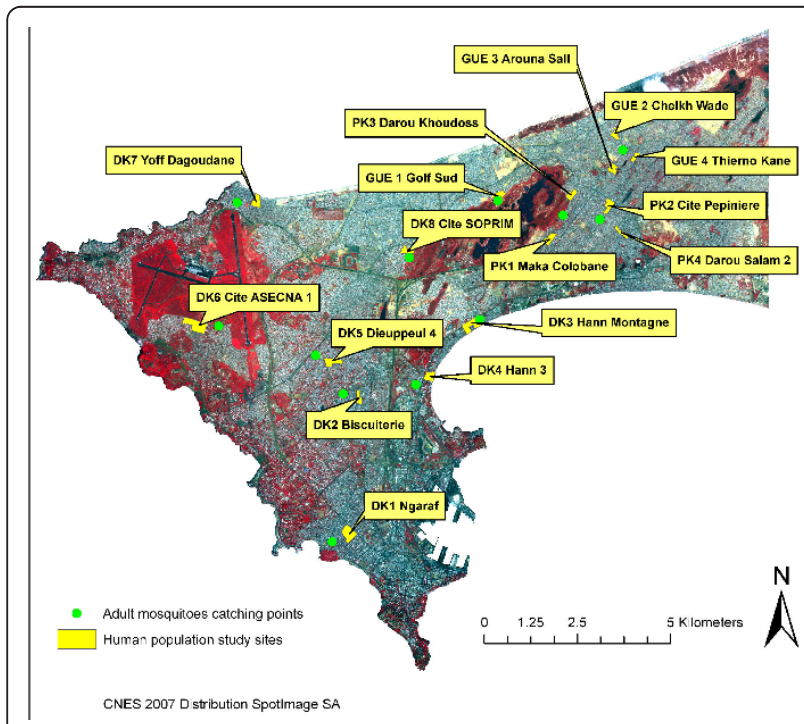

Figure 1 Localization of the studied sites in Dakar. The 12 adult mosquito-catching (in green) and the 16 blood spot-sampling (in yellow) sites are localized on the map. An adult mosquito catching point allowed an estimate of An. gambiae intensity of exposure in two (PK 2 and PK 4) or three (GUE 1, GUE 2 and GUE 3) neighbouring blood spot-sampling sites. DK, PK and GUE are respectively Dakar, Pikine and Guediawaye, departments of Dakar region. The brown base of the map represents the area without human habitations. Its darkness is correlated to the presence of vegetation. occurs from July to December, with a peak from September to November $[9,10,13]$.

\section{Study design}

Dakar region comprises 42 urban districts (UDs), which are constituted by about 2,000 census districts (CDs), the smallest level in terms of demographic inventory in Senegal. This work began by mapping individual and household information (socio-cultural and demographic characteristics, economic level) stemming from the general inventory of the Senegalese population and housing of 2002. An analysis of the main socio-demographic and economic variables, using principal component analysis and the k-means clustering method, was performed and allowed to classify CDs in five types. One of the most representative types in each UD was randomly chosen; $42 \mathrm{CDs}$ were then selected. To reach the number of 50 sites planned for the study, eight other CDs were added according to their socio-demographic characteristics and their proximity to shallows in order to get more information on districts with the highest risk of malaria. Selected CDs were visited by one of the five teams of investigators according to itineraries pre-established by the head-supervisor; 60 households in each CDs $(3,000$ households for the 50 sites) were selected and identified. The first criterion of a household selection was the presence of a two to 10 years-old child resident. After having the written agreement of resident family, investigators crossed a questionnaire about the household lifestyle, income and the access mode to healthcare facilities. Concomitantly, the adult woman (generally the child's mother) who answered the questionnaire was selected for blood sampling. Pregnant women, individuals who were sick and/or have taken anti-malarial drugs during the last 15-30 days preceded nurses' passage were not included in the cohort.

In total, due to refusal or exclusion criteria, 4,658 individuals $(2,231$ children and 2,427 adults, women in majority) from 50 sites of Dakar region were included in the study. A dried blood spot for immunological analysis were collected for each individual. Results are presented here for a sub-sample of 1,010 individuals (505 children two to 10 years old and 505 women $>18$ years (adults)) randomly sampled within $16 \mathrm{CDs}$ for which entomological data are available (Figure 1). The number of individuals (children and women) for whom IgG Ab responses were assessed varied by site, from 56 in DK 1 to 76 in DK 3 (Table 1).

In the immunological sub-sample, the median age was $5.0(\mathrm{Q} 25 \%=3.0$ and $\mathrm{Q} 75 \%=8.0)$ in children and 35.0 $(\mathrm{Q} 25 \%=28.0$ and $\mathrm{Q} 75 \%=42.0)$ years old in adult women of all districts. The median age was similar between districts, except in women where it was significantly different only between PK 4 and DK 7 and 
Table 1 Blood sampling and entomological survey periods

\begin{tabular}{|c|c|c|c|c|c|}
\hline Districts name & Districts code & Blood sampling dates & $\mathrm{n}$ & Benning of mosquitoes sampling & Number of sampling nights* \\
\hline$\overline{\text { Ngaraf }}$ & DK 1 & Dec-08 & 56 & Aug-08 & 10 \\
\hline Biscuiterie & DK 2 & Dec-08 & 60 & Aug-08 & 9 \\
\hline Hann Montagne & DK 3 & Oct-08 & 76 & Jul-08 & 6 \\
\hline Hann 3 & DK 4 & Oct-08 & 64 & Jul-08 & 6 \\
\hline Dieupeul 4 & DK 5 & Nov-08 & 58 & Aug-08 & 7 \\
\hline Cité ASECNA 1 & DK 6 & Oct-08 & 70 & Aug-08 & 5 \\
\hline Yoff Dagoudane & DK 7 & Nov-08 & 62 & Aug-08 & 8 \\
\hline Cite SOPRIM & DK 8 & Oct-08 & 58 & Jul-08 & 7 \\
\hline Golf Sud & GUE 1 & Nov-08 & 64 & Aug-08 & 9 \\
\hline Cheikh Wade & GUE 2 & Nov-08 & 60 & Aug-08 & 8 \\
\hline Arouna Sall & GUE 3 & Nov-08 & 62 & Aug-08 & 9 \\
\hline Thierno Kane & GUE 4 & Nov-08 & 70 & Aug-08 & 8 \\
\hline Maka Colobane & PK 1 & Nov-08 & 60 & Jul-08 & 8 \\
\hline Cité Pépinière & PK 2 & Nov-08 & 62 & Jul-08 & 9 \\
\hline Darou Khoudoss & PK 3 & Nov-08 & 58 & Jul-08 & 9 \\
\hline Darou Salam 2 & PK 4 & Nov-08 & 70 & Jul-08 & 8 \\
\hline
\end{tabular}

DK (= Dakar), GUE (Guédiawaye) and PK (Pikine) are initials of the names of the department of the studied district. " $\mathrm{n}$ " represents the number of individuals blood-sampled for immunological assays in each district. The number of sampling-nights is reported for each district from the first entomological survey day (during the beginning of the transmission period) to the beginning of blood spot samplings in the concerning district

between PK 4 and PK 1 ( $\mathrm{p}<0.05)$. This study was conducted in accordance with the Edinburgh revision of the Helsinki Declaration, and was approved by the ethical committees of the Ministry of Health and Prevention of Senegal (December 2008). Written informed consent was obtained for all individuals enrolled in the study. For children, this informed consent was signed by one of their parents or their tutor (child guardian).

\section{Entomological analysis}

Adult mosquito samplings were carried out once every two weeks during the study period in 12 study sites located in downtown Dakar and its closed suburbs (Pikine and Guédiawaye) from July 2008 to the date of blood-spot samplings (October to December 2008 according to CDs). Human-landing catches of adult mosquitoes were conducted both indoor (one catching point) and outdoor (two catching points) in or near (less than 250-300 $\mathrm{m}$ from the epicentre of the CD) each $C D$. Five to 10 study nights were carried out according to CDs. Indoor captures were conducted with the window or door slightly ajar. Collectors gave prior informed consent and received yellow fever vaccination and anti-malarial chemoprophylaxis consisting of 100 mg doxycycline per day for the duration of the study and one month after. Two collectors were contracted for each catching point to work from 8:00 p.m. to 7:00 a.m., with each one resting every two hours. Collectors were rotated among the catching points on different collection nights to minimize sampling bias. The mosquitoes were recorded by catching point, date and hour of capture and they were sorted by genera. The
Anopheline mosquitoes were identified morphologically following the Gillies and Coetzee keys [39]. The human biting rate (HBR) was expressed as the number of female An. gambiae s.l. per person per night, averaged for both outdoor and indoor catching points. Thus, the HBR for each district accounted for the average cumulative bites per person per night received before the blood sampling.

\section{Salivary peptide gSG6-P1}

The gSG6-P1 peptide was designed using bioinformatics to maximize its Anopheles specificity and its antigenicity, as previously described [36]. The gSG6-P1 peptide was synthesized, purified (> 95\%) by Genepep SA (St-Clément de Rivière, France). All peptide batches were shipped in lyophilized form and then suspended in $0.22 \mu \mathrm{m}$ ultra-filtered water and frozen in aliquots at $80^{\circ} \mathrm{C}$ until use for immunological tests (ELISA).

\section{Evaluation of human IgG antibody levels (ELISA)}

Standardized dried blood spots (80 mm diameter) were eluted as previously described [31]. ELISAs were carried out on dried blood-spot eluates to assay IgG response to the gSG6-P1 antigen as previously described [35]. Individual results were expressed as the $\triangle \mathrm{OD}$ value: $\triangle \mathrm{OD}=$ ODxODn, where ODx represents the mean of individual optical density (OD) in both antigen wells and ODn the individual OD in a blank well containing no gSG6-P1 antigen. Specific anti-gSG6-P1 IgG levels were also assayed in non-Anopheles exposed individuals $(\mathrm{n}=14$ neg; North of France) in order to quantify the non-specific background Ab level and to calculate the cut-off of 
immune response (threshold of immune response or TR $=$ mean $\left.\left(\Delta \mathrm{DO}_{\text {neg }}\right)+3 \mathrm{SD}=0.204\right)$. An exposed individual was then classified as an immune responder if its $\Delta \mathrm{OD}>0.204$

\section{Statistical analysis}

All data were analysed with GraphPad Prism5 software ${ }^{\circledR}$ (San Diego, CA, USA). The non-parametric MannWhitney $U$-test was used for comparison of median $\mathrm{Ab}$ levels between children and adult women of each district, the non-parametric Kruskal-Wallis test for comparison of medians for more than two groups and the Fischer exact test for comparison between two proportions. A simple linear regression was used to evaluate association level between IgG responses and exposure levels to An. gambiae s.l. bites (HBR). Statistical significant difference between the three defined groups of exposure has been assessed using an ANOVA simple test. All differences were considered significant at $\mathrm{P}<$ 0.05 .

\section{Results}

Specific IgG responses to gSG6-P1 peptide according to districts

Specific IgG Ab levels to gSG6-P1 peptide were evaluated according to studied sites (CDs) and presented for children (Figure 2A) and adult women (Figure 2B). Results of this analysis show considerable variations within and between studied CDs. In spite of the interindividual heterogeneity at $\mathrm{CD}$ level, the median of specific IgG Ab levels in children as well as in adults differed significantly $(\mathrm{P}<0.0001)$ between CDs. Moreover, CDs presenting high or low specific IgG levels in children were the same where high or low IgG Ab levels were respectively observed in adult women. The median of specific IgG Ab levels was particularly high in DK 3 and DK 6, in GUE 1 and in PK 1 and PK 3 and low in DK1, DK 2, DK 7 and DK 8 (four populous districts of Dakar), in GUE 3 and in PK 2 and PK 4 (suburbs of Dakar region). In addition, in the majority of districts $(13 / 16)$, the median of anti-gSG6-P1 IgG levels seemed to be higher in adult women (Figure 2B) than in children (Figure 2A) but this difference was not significant, except in DK $8(\mathrm{P}=0.01)$.

As observed for median of specific IgG Ab levels percentages of individual immune responders (individuals with $\Delta \mathrm{OD}>0.204=\mathrm{TR}$ ) were fairly high (minimum: $43.55 \%$ in GUE 3 and maximum: $86.84 \%$ in DK 3 ) and varied according to CDs (Table 2). Indeed, the lowest percentage of responders were observed in GUE 3 (43.55\%), DK 1 (50.00\%), DK 2 (50.00\%), PK 4 (54.29\%) and DK 7 (54.84\%) and the highest in DK 6 (74.29\%), GUE 1 (81.25\%), PK 3 (82.76\%), PK 1 (83.33\%) and DK 3 (86.84\%). The use of median IgG level or the percentage of immune responders appeared, therefore, to give similar results for the classification of CDs as high or low anti-gSG6-P1 IgG response.

\section{Specific lgG responses and intensities of exposure to Anopheles gambiae sensu lato bites}

Correlations between immunological parameters, i.e. the human IgG level (Figure 3A) and the percentage of immune responders (Figure 3B) to gSG6-P1 peptide, and entomological data, the number of $A n$. gambiae s.l bites/human/night (HBR), are presented for all studied population (children and adult women).

The entomological data (Table 2) indicate that the intensity of exposure $A n$. gambiae s.l. bites was globally low and changed also according to $\mathrm{CDs}$ ( $\mathrm{HBR}=0.3$ in DK 1 to 121.4 in GUE 1 ). It was positively and significantly correlated to medians of specific IgG levels $\left(\mathrm{R}^{2}=\right.$ 0.54; Figure $3 \mathrm{~A}$ ) and to the percentage of immune responders $\left(R^{2}=0.51\right.$; Figure $\left.3 B\right)$. Similar correlation trends were also observed when specific IgG data are separately analysed for children and adult women. Indeed, exposure levels to An. gambiae s.l were positively associated to anti-gSG6-P1 IgG levels and to the percentage of anti-gSG6-P1 IgG responders in children $\left(\mathrm{R}^{2}=0.54\right.$ with $\mathrm{p}=0.001$ and $\mathrm{R}^{2}=0.33$ with $\mathrm{p}=0.02$, respectively) and in adult women $\left(R^{2}=0.30\right.$ with $p=$ 0.03 and $R^{2}=0.59$ with $p=0.0005$, respectively) (graphs not shown). Interestingly, in the studied districts, $A n$. gambiae s. $l$. HBR appeared to be highly correlated to medians of specific IgG levels in adult women, whereas they were more clearly correlated to percentages of immune responders in children.

However, results show some discrepancies between immunological and entomological results in some CDs. Indeed, low specific IgG levels and/or percentage of responders could be observed in CD where high HBR were detected and vice versa (Table 2). For example, GUE $3(\mathrm{HBR}=6.6)$ presented low specific IgG level and/or percentage of responders than DK 1 (HBR = $0.3)$, DK $2(\mathrm{HBR}=0.8)$, DK $5(\mathrm{HBR}=1.5)$ and $\mathrm{DK} 7$ $(\mathrm{HBR}=0.4)$. In contrast, $\mathrm{PK} 3(\mathrm{HBR}=33.7)$ presented a higher percentage of responders than DK 8 (HBR = 46.0) and GUE $1(\mathrm{HBR}=121.4)$.

\section{IgG response to gSG6-P1 peptide as an indicator for a} reliable evaluation of urban exposure level to Anopheles gambiae s.l. bites

The first step was to classify the districts within three groups (gr. 1 = low; gr. 2 = medium and gr. $3=$ high level), based to the percentage of immune responders and the medians of specific IgG responses, as described in Table 2. As expected, the percentage of immune responders and the specific IgG level increased according the immunological groups and were highly different 


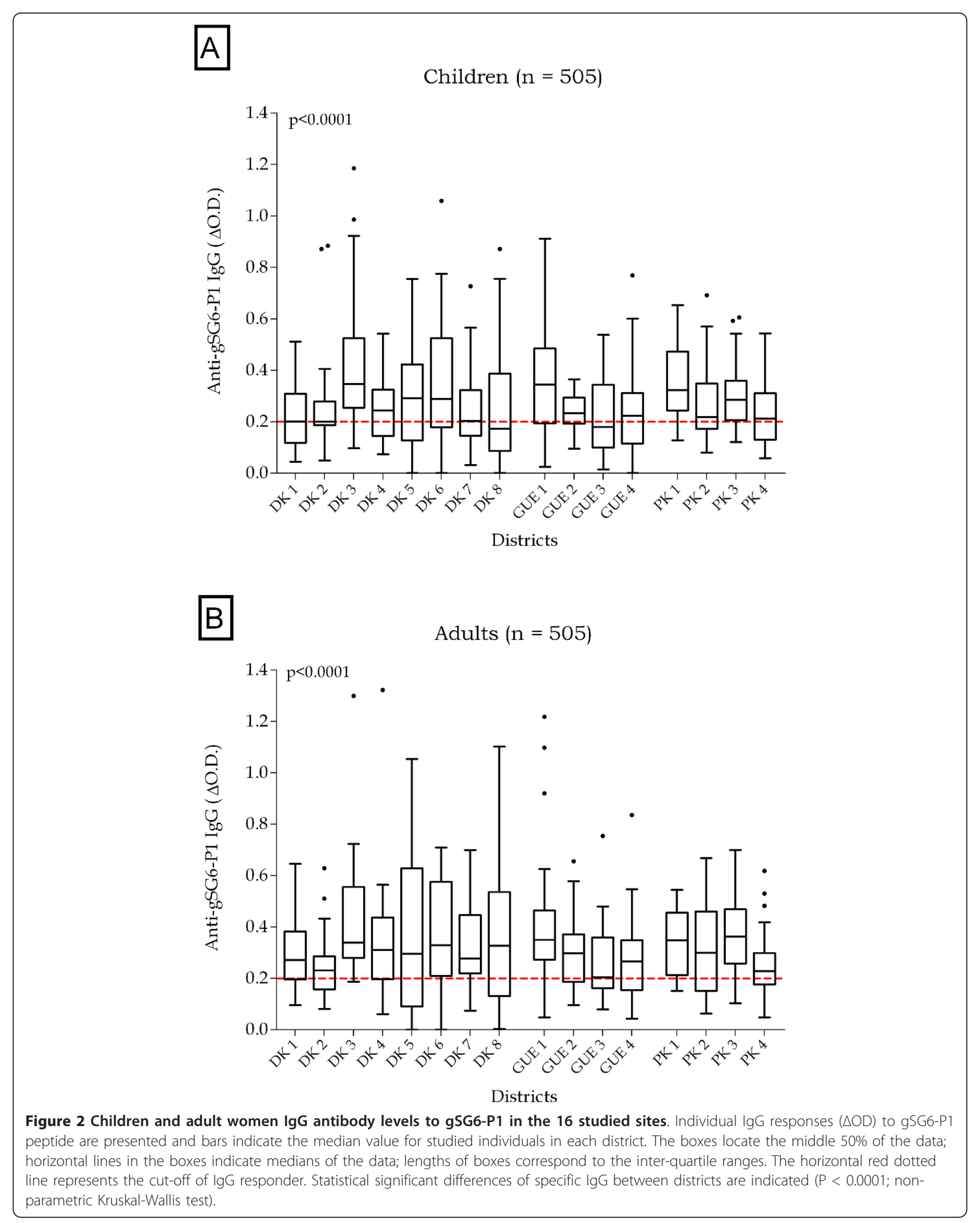


Table 2 Constitution of exposure groups according to percentages of immune responders and median anti-gSG6-P1 IgG responses

\begin{tabular}{|c|c|c|c|c|c|c|c|}
\hline $\begin{array}{l}\text { "Exposure" } \\
\text { groups }\end{array}$ & $\begin{array}{l}\text { Districts } \\
\text { code }\end{array}$ & $\begin{array}{l}\% \text { of anti-gSG6-P1 } \\
\text { responders }\end{array}$ & $\begin{array}{c}\text { Rank } \\
1\end{array}$ & $\begin{array}{c}\text { Median of anti-gSG6-P1 } \\
\text { lgG }\end{array}$ & $\begin{array}{c}\text { Rank } \\
2\end{array}$ & $\begin{array}{c}\text { Rank } \\
\text { sum }\end{array}$ & $\begin{array}{c}\text { An. gambiae Bites/Human/ } \\
\text { Nigh }\end{array}$ \\
\hline \multirow[t]{4}{*}{ Group 1} & GUE 3 & 43.55 & 1 & 0.189 & 1 & 2 & 6.6 \\
\hline & DK 2 & 50,00 & 3 & 0.209 & 2 & 5 & 0.3 \\
\hline & DK 1 & 50,00 & 2 & 0.234 & 4 & 6 & 0.8 \\
\hline & PK 4 & 54.29 & 4 & 0.213 & 3 & 7 & 14.3 \\
\hline \multirow[t]{7}{*}{ Group 2} & DK 7 & 54.84 & 5 & 0.262 & 7 & 12 & 0.4 \\
\hline & GUE 4 & 61.43 & 7 & 0.253 & 5 & 12 & 7.4 \\
\hline & PK 2 & 59.68 & 6 & 0.264 & 9 & 15 & 14.3 \\
\hline & DK 4 & 64.06 & 9 & 0.262 & 8 & 17 & 17.1 \\
\hline & GUE 2 & 70,00 & 11 & 0.255 & 6 & 17 & 7.4 \\
\hline & DK 5 & 62.07 & 8 & 0.292 & 11 & 19 & 1.5 \\
\hline & DK 8 & 65.52 & 10 & 0.273 & 10 & 20 & 46.0 \\
\hline \multirow[t]{5}{*}{ Group 3} & DK 6 & 74.29 & 12 & 0.328 & 14 & 26 & 26.2 \\
\hline & PK 3 & 82.76 & 14 & 0.316 & 12 & 26 & 33.9 \\
\hline & GUE 1 & 81.25 & 13 & 0.350 & 15 & 28 & 121.4 \\
\hline & PK 1 & 83.33 & 15 & 0.323 & 13 & 28 & 37.0 \\
\hline & DK 3 & 86.84 & 16 & 0.350 & 15 & 31 & 82.9 \\
\hline
\end{tabular}

Districts are classed in an ascending order according to their proportion of anti-gSG6-P1 IgG immune responders (Rank 1 column) and the median of specific lgG level (Rank 2 column). A rank number was assigned to each district according its position in the considering rank column. The sum of the two rank numbers of each district was realized

between each pair of groups $(\mathrm{p}<0.0001)$. The intensity of exposure levels to An. gambiae bites (HBR) evaluated by classical entomological methods was then compared between the three groups of immune response (Figure 4 ). It increased according to the groups of immune response. However, this difference was only clear when taking into account the group presenting the highest level of specific immune response (group 3). Indeed, the intensity of exposure levels (HBR), showed significant differences only in comparing group 3 versus group 1 and group 3 versus group 2. No significant difference was observed between group 1 and group 2 (Figure 4).

\section{Discussion}

The present study focused on the application of the Anopheles gSG6-P1 salivary biomarker in the evaluation of the exposure level to vector bites in low-urban malaria settings. Firstly, data of the study have shown a high heterogeneity of specific IgG Ab response to this salivary peptide between individuals, i) within each studied district, and ii) between the 16 studied districts of Dakar and its suburbs. These observations suggest in this urban area important differences in the humanAnopheles contact level which could be influenced by several individual and/or household factors and behaviours [40]. For example, the use of vector control strategies [41] and movements of urban populations to rural areas, where exposure to Anopheles bites is higher [7], can increase/decrease significantly the probability of contact between human hosts and malaria vectors and explain a part of observed immunological results. But some epidemiological factors such as genetic, co-infection, nutritional parameters, could not be excluded. Nevertheless, these results strengthen previous clear data that validated this salivary peptide of $A n$. gambiae as a relevant tool biomarker to assess the human exposure level to malaria vectors bites in other exposure and malaria transmission settings [18,35-37].

Secondly, results have shown that immunological data were positively correlated to An. gambiae s.l. human biting rates (HBR). This result suggests that differences in exposure levels to An. gambiae bites in the Dakar area could partly explain the variations in anti-gSG6-P1 IgG $\mathrm{Ab}$ response observed between districts and groups of exposure. Similar observations were reported in previous studies carried out in individuals exposed to An. gambiae bites in a rural area of Senegal [18] and semi-urban area of Angola. However, in urban settings, differences in exposure level to Anopheles bites between neighbouring districts can be generated by local differences in larval breeding sites which are mostly localized and advantaged or disadvantaged by many environmental modifications [13]. They could be also linked to the low dispersion capacity of $A n$. gambiae s. $l$. populations in urban areas (less than $300 \mathrm{~m}$ from their breeding sites) due to the high density of human populations [14] and their high availability as hosts for Anopheles bites $[14,42]$. In the Dakar area, recent studies have reported the existence of farming and gardening in some districts of Hann-Yarakh (including DK 3 and DK 4), Golf Sud 
A

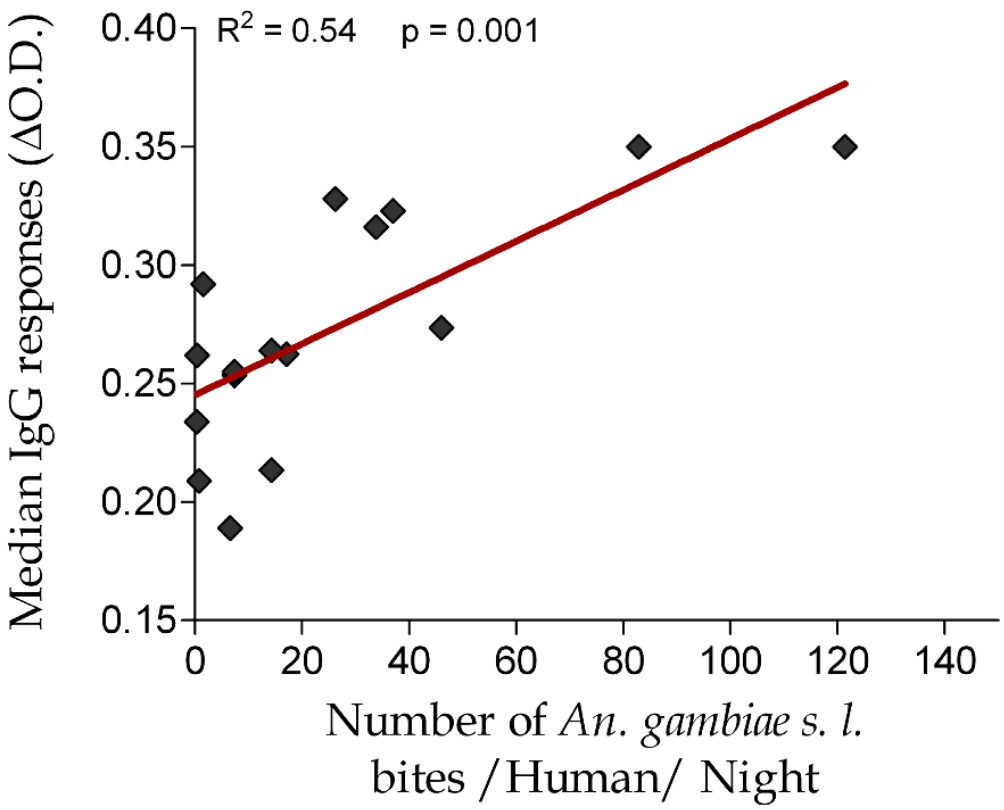

B

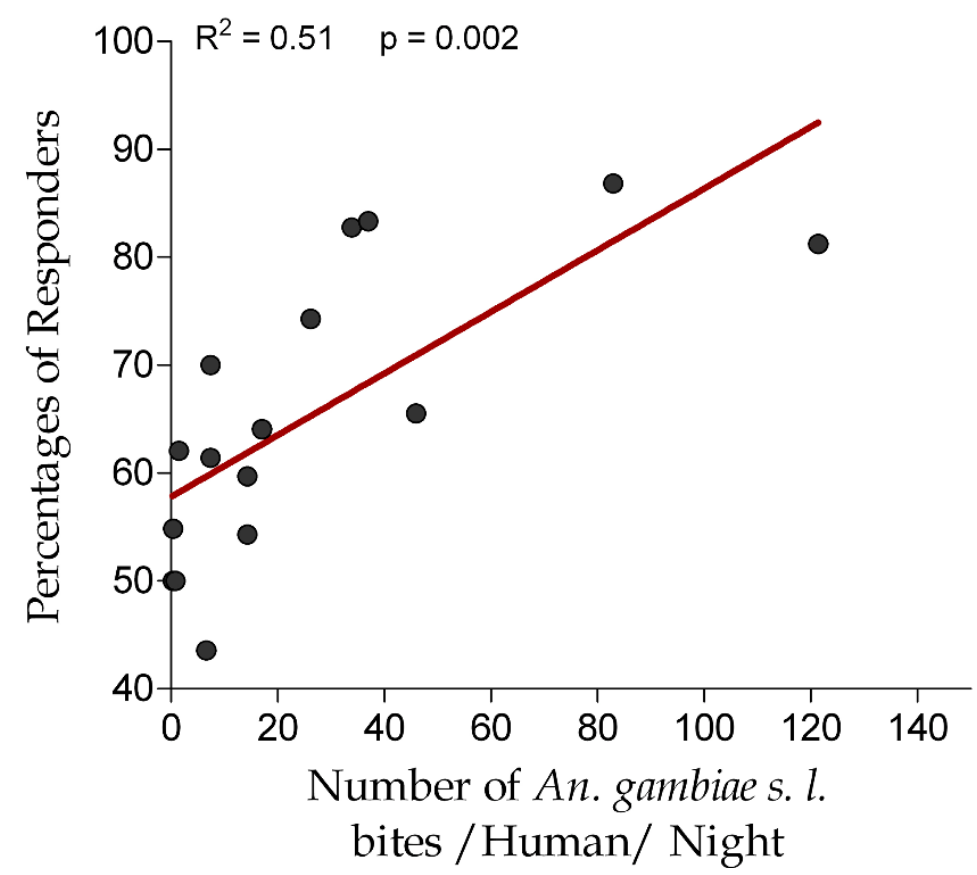

Figure $3 \mathrm{lgG}$ response to gSG6-P1 and intensity of exposure to Anopheles gambiae sensu lato according to the studied sites. The medians of anti-gSG6-P1 lgG levels (Figure 3A) and the percentages of immune responders (Figure 3B) for all individuals (children and adults) are correlated to the number of An. gambiae bites/human/night according to districts. Black rhombus and black circles represent respectively median anti-sGS6-P1 lgG levels and percentage of human responders in the 16 CDs. The red solid line indicates the correlation line between each immunological parameter and the An. gambiae s. I. human biting rate. Statistical significant linear associations are indicated (simple linear regression method). 


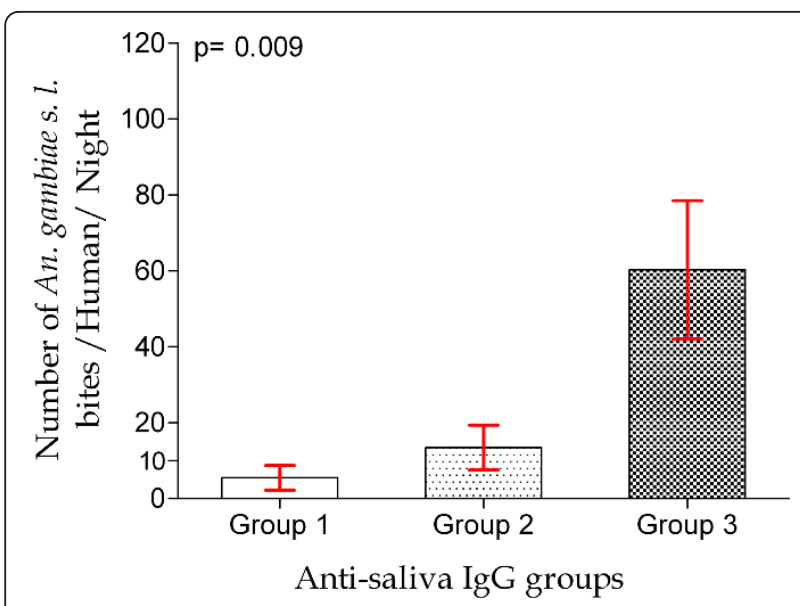

Figure 4 Intensity of exposure to Anopheles gambiae sensu lato according to the three immunological exposure groups. Data present the mean of the number of An. gambiae bites/human/night according to the three defined exposure groups. Statistical significant difference between the three groups is indicated using an ANOVA simple test and differences between each pair of groups by the Bonferroni's Multiple Comparison Test.

(GUE 1) and Pikine (PK 1 and PK 3) areas [11,13] where high levels of specific anti-gSG6-P1 IgG responses were observed. But, irrigation practices seemed here to be extremely rare or inexistent, in contrast to observations reported in urban cities of Ivory Coast [43] and Ghana [44].

However, discrepancies observed in the correlation between immunological parameters and the exposure level to An. gambiae bites in some CDs (GUE 3 for example) suggest that other factors may contribute to explain the variation in individual IgG responses to gSG6-P1 peptide, and then human-Anopheles mosquitoes contact. For example, a differential use of vector control tools (ITNs, sprays, curtains) can reduce drastically human-vector contact. Many household characteristics (height, type, use of air conditioning, well-closed windows), which can differ between districts, could also be crucial factors. This study highlights then the pertinence of the use of this peptide biomarker for evaluating the individual and population exposure to bites and the efficacy of vector control devices as it has been demonstrated in a semi-urban area [35].

Thirdly, it has observed that the means of exposure intensity to An. gambiae bites were significantly different only between the high immune response group and the two other groups (medium and low level). This observation deals with the usefulness of such biomarker in the evaluation of exposure levels to bites, especially in low/very low exposure contexts (for example immune response groups 1 and 2), where current entomological methods can give inaccurate estimations of the human- mosquito contact as also previously observed [18]. However, the present entomological data must be interpreted with cautious. Indeed, mosquitoes' catch sites were sometimes more than 250-300 m distant from the epicentre of human blood sampling site and might not reliably evaluate An. gambiae s.l. HBR in concerned areas.

The gSG6-P1 peptide was designed on the basis of the An. gambiae s.s. sequence, the only Anopheles genome completely available [45]. In the studied area, species of $A n$. gambiae complex, especially $A n$. arabiensis and $A n$. melas, are the main vectors of P. falciparum [10]. Anopheles pharoensis has been also described in few quantities, but was not associated to Plasmodium transmission [13]. It can be hypothesized that the exposure of individuals to these Anopheles anthropophagic vectors has been evaluated using this salivary peptide, which is highly conserved between Anopheles species [36,46]. Indeed, it has been shown that gSG6-P1 peptide shares $82 \%$ and 91\% identity with Anopheles stephensi and An. funestus and that IgG response to this peptide was also biomarker of An. funestus exposure [37]. All these data tend to support the proposal that gSG6-P1 can be used reliably to evaluate children and adults low-exposure levels to major Anopheles species known to be vector of malaria in sprawling African cities, and then to assess malaria risk in such areas.

\section{Conclusions}

To identify new biomarkers for malaria risks, an efficient tool based on the measurement of human IgG Ab responses to specific gSG6-P1 peptide represents a new way to evaluate accurately the heterogeneity of exposure level to bites at population and at individual levels. This approach appears to be promising and complementary to classical entomological methods, because it can give a reliable evaluation of the individual contact with anthropophilic Anopheles in particular low exposure urban areas. This biomarker could be particularly relevant in mapping malaria risk in urban settings, but also in high -altitude or seasonal malaria, and in travellers in endemic areas. It could also represent an alternative way to obtain new criteria for measuring the efficacy of the specific vector control strategies used in urban settings and allow then a pertinent monitoring of strategies developed by the National Malaria Control Programmes in African urban contexts.

\section{Acknowledgements}

We thank all the participants in the study and the technical and useful assistance of Alphousseyni Ndonky, Aguibou Diallo and Assane Diop. We thank also the CNES ISIS program, which provided access to high spatial resolution SPOT5 images. This article is published with the permission of the Ministry of Health and Prevention of Senegal and the "Institut de Recherche pour le Développement (IRD)". The work was supported by ANR (Agence Nationale pour la Recherche) grant n²007 SEST 00102 and by IRD 
(Département de la Valorisation au Sud: DVS). PMD was supported by a PhD scholarship provided by IRD (DSF Department) then a fellowship from InfectioPole Sud Fundation. VM received financial support from the Direction Générale de l'Armement (DGA-Contrat d'Objectif n'07CO402) and the Centre National d'Etudes Spatiales (CNES). AD is a PhD student supported by IRDDSF Department. AP was supported by a fellowship from F. Lacoste.

\section{Author details}

'Unité Mixte de Recherche MIVEGEC (IRD 224-CNRS 5290-UM1), Institut de Recherche pour le Développement, 34394, Montpellier Cedex 8, France. 2Unité Mixte de Recherche 6236 (URMITE), Institut de Recherche Biomédicale des Armées, Allée du Médecin Colonel Jamot, 13262, Marseille Cedex 07, France. ${ }^{3}$ Observatoire Midi-Pyrénées, Laboratoire d'Aérologie, Centre National de le Recherche Scientifique, Université Paul Sabatier, 31400, Toulouse, France. ${ }^{4}$ Centre National d'Etudes Spatiales, Service Applications et Valorisation, 31401, Toulouse Cedex 9, France. ${ }^{5}$ IRD/UMR 216-Mère et Enfant face aux Infections Tropicales, Faculté des Sciences Pharmaceutiques, 4 avenue de l'Observatoire, 75270, Paris Cedex 06, France. ${ }^{6}$ Unité Mixte de Recherche 151, Institut de Recherche pour le Développement, Université de Provence, 13331, Marseille Cedex 03, France. ${ }^{7}$ Département de Biologie Animale, Université Cheikh Anta DIOP, Dakar BP-5005, Sénégal. ${ }^{8}$ Unité Mixte de Recherche 151, Institut de Recherche pour le Développement, Campus International de Recherche UCAD/IRD de Hann, Dakar BP 1386, Sénégal. ${ }^{9}$ Institut Pasteur de Madagascar, B.P. 1274, Ambatofotsikely, Antananarivo 101, Madagascar. ${ }^{10}$ Unité Mixte de Recherche MIVEGEC (IRD 224-CNRS 5290UM1), Institut de Recherche pour le Développement, Centre de Recherche Entomologique de Cotonou (CREC), BP-4414, Cotonou, RP 01, Benin.

\section{Authors' contributions}

PMD and VM participated in field surveys, assembled and analysed data and drafted the manuscript. AD participated in study coordination, field surveys and data collection. SC and AP participated in manuscript preparation, writing and revision. SD and RL coordinated the study and revised the manuscript. MS helped with manuscript preparation and revised the manuscript. JYH (participated also to the study coordination); CR and FP designed the study, helped with manuscript preparation and revised the manuscript. FR participated in study design, preparation and writing of the manuscript and revised the manuscript. All authors read and approved the final manuscript.

\section{Competing interests}

The authors declare that they have no competing interests.

Received: 2 January 2012 Accepted: 16 March 2012

Published: 16 March 2012

\section{References}

1. Guerra CA, Gikandi PW, Tatem AJ, Noor AM, Smith DL, Hay SI, Snow RW: The limits and intensity of Plasmodium falciparu transmission: implications for malaria control and elimination worldwide. PLOS Med 2008, 5:e38.

2. Martens $P$, Hall $L$ : Malaria on the move: human population movement and malaria transmission. Emerg Infect Dis 2000, 6:103-109.

3. Tatem AJ, Guerra CA, Kabaria CW, Noor AM, Hay SI: Human population, urban settlement patterns and their impact on Plasmodium falciparu malaria endemicity. Malar J 2008, 7:218.

4. Wang SJ, Lengeler C, Smith TA, Vounatsou P, Cisse G, Diallo DA Akogbeto M, Mtasiwa D, Teklehaimanot A, Tanner M: Rapid urban malaria appraisal (RUMA) in sub-Saharan Africa. Malar J 2005, 4:40.

5. Keiser J, Utzinger J, Caldas de Castro M, Smith TA, Tanner M, Singer BH: Urbanization in sub-saharan Africa and implication for malaria control. Am J Trop Med Hyg 2004, 71:118-127.

6. Chinery WA: Effects of ecological changes on the malaria vectors Anopheles funestus and the Anopheles gambia complex of mosquitoes in Accra, Ghana. J Trop Med Hyg 1984, 87:75-81.

7. Robert V, Macintyre K, Keating J, Trape JF, Duchemin JB, Warren M, Beier JC: Malaria transmission in urban sub-Saharan Africa. Am J Trop Med Hyg 2003, 68:169-176.

8. Donnelly MJ, McCall PJ, Lengeler C, Bates I, D'Alessandro U, Barnish G, Konradsen F, Klinkenberg E, Townson H, Trape JF, Hastings IM, Mutero C: Malaria and urbanization in sub-Saharan Africa. Malar J 2005, 4:12.
9. Diallo S, Konate L, Ndir O, Dieng T, Dieng Y, Bah IB, Faye O, Gaye O: Malaria in the central health district of Dakar (Senegal). Entomological, parasitological and clinical data. Sante 2000, 10:221-229.

10. Gadiaga L, Machault V, Pages F, Gaye A, Jarjaval F, Godefroy L, Cisse B, Lacaux JP, Sokhna C, Trape JF, Rogier C: Conditions of malaria transmission in Dakar from 2007 to 2010. Malar J 2011, 10:312.

11. Pages F, Texier G, Pradines B, Gadiaga L, Machault V, Jarjaval F, Penhoat K, Berger F, Trape JF, Rogier C, Sokhna C: Malaria transmission in Dakar: a two-year survey. Malar J 2008, 7:178.

12. Trape JF, Lefebvre-Zante $E$, Legros F, Ndiaye $G$, Bouganali $H$, Druilhe $P$, Salem G: Vector density gradients and the epidemiology of urban malaria in Dakar, Senegal. Am J Trop Med Hyg 1992, 47:181-189.

13. Machault V, Gadiaga L, Vignolles C, Jarjaval F, Bouzid S, Sokhna C, Lacaux JP, Trape JF, Rogier C, Pages F: Highly focused anopheline breeding sites and malaria transmission in Dakar. Malar J 2009, 8:138

14. Machault V, Vignolles C, Pages F, Gadiaga L, Gaye A, Sokhna C, Trape JF, Lacaux JP, Rogier C: Spatial heterogeneity and temporal evolution of malaria transmission risk in Dakar, Senegal, according to remotely sensed environmental data. Malar J 2010, 9:252.

15. Govella NJ, Chaki PP, Geissbuhler Y, Kannady K, Okumu F, Charlwood JD, Anderson RA, Killeen GF: A new tent trap for sampling exophagic and endophagic members of the Anopheles gambia complex. Malar J 2009, 8:157.

16. Mathenge EM, Omweri GO, Irungu LW, Ndegwa PN, Walczak E, Smith TA, Killeen GF, Knols BG: Comparative field evaluation of the Mbita trap, the Centers for Disease Control light trap, and the human landing catch for sampling of malaria vectors in western Kenya. Am J Trop Med Hyg 2004, 70:33-37.

17. Mboera LE: Sampling techniques for adult Afrotropical malaria vectors and their reliability in the estimation of entomological inoculation rate. Tanzan Health Res Bull 2005, 7:117-124.

18. Poinsignon A, Cornelie S, Ba F, Boulanger D, Sow C, Rossignol M, Sokhna C, Cisse B, Simondon F, Remoue F: Human IgG response to a salivary peptide, gSG6-P1, as a new immuno-epidemiological tool for evaluating low-level exposure to Anopheles bites. Malar J 2009, 8:198.

19. Remoue F, Cornelie S, Ngom A, Boulanger D, Simondon F: Immune responses to arthropod bites during vector-borne diseases. In Update in tropical immunology Edited by: Garraud O Fort PO Trivandrum, Herala, India: Transworld research Network 2005, 377-400.

20. Schwartz BS, Ribeiro JM, Goldstein MD: Anti-tick antibodies: an epidemiologic tool in Lyme disease research. Am J Epidemiol 1990, 132:58-66.

21. Champagne DE: Antihemostatic strategies of blood-feeding arthropods. Curr Drug Targets Cardiovasc Haematol Disord 2004, 4:375-396.

22. Ribeiro JM: Blood-feeding arthropods: live syringes or invertebrate pharmacologists? Infect Agents Dis 1995, 4:143-152.

23. Brummer-Korvenkontio H, Palosuo K, Palosuo T, Brummer-Korvenkontio M, Leinikki P, Reunala T: Detection of mosquito saliva-specific IgE antibodies by capture ELISA. Allergy 1997, 52:342-345.

24. Lane RS, Moss RB, Hsu YP, Wei T, Mesirow ML, Kuo MM: Anti-arthropod saliva antibodies among residents of a community at high risk for Lyme disease in California. Am J Trop Med Hyg 1999, 61:850-859.

25. Barral A, Honda E, Caldas A, Costa J, Vinhas V, Rowton ED, Valenzuela JG, Charlab R, Barral-Netto M, Ribeiro JM: Human immune response to sand fly salivary gland antigens: a useful epidemiological marker? Am J Trop Med Hyg 2000, 62:740-745.

26. Nascimento RJ, Santana JM, Lozzi SP, Araujo CN, Teixeira AR: Human IgG1 and IgG4: the main antibodies against Triatoma infestan (Hemiptera: Reduviidae) salivary gland proteins. Am J Trop Med Hyg 2001, 65:219-226.

27. Poinsignon $A$, Remoue $F$, Rossignol M, Cornelie $S$, Courtin D, Grebaut $P$, Garcia A, Simondon F: Human IgG antibody response to Glossina saliva: an epidemiologic marker of exposure to Glossina bites. Am J Trop Med Hyg 2008, 78:750-753.

28. Palosuo K, Brummer-Korvenkontio H, Mikkola J, Sahi T, Reunala T: Seasonal increase in human IgE and lgG4 antisaliva antibodies to Aedes mosquito bites. Int Arch Allergy Immunol 1997, 114:367-372.

29. Remoue F, Alix E, Cornelie S, Sokhna C, Cisse B, Doucoure S, Mouchet F, Boulanger D, Simondon F: IgE and IgG4 antibody responses to Aedes saliva in African children. Acta Trop 2007, 104:108-115. 
30. Peng Z, Rasic N, Liu Y, Simons FE: Mosquito saliva-specific IgE and IgG antibodies in 1059 blood donors. J Allergy Clin Immunol 2002, 110:816-817.

31. Drame PM, Poinsignon A, Besnard P, Le Mire J, Dos-Santos MA, Sow CS, Cornelie S, Foumane V, Toto JC, Sembene M, Boulanger D, Simondon F, Fortes F, Carnevale P, Remoue F: Human antibody response to Anopheles gambia saliva: an immuno-epidemiological biomarker to evaluate the efficacy of insecticide-treated nets in malaria vector control. Am J Trop Med Hyg 2010, 83:115-121.

32. Remoue F, Cisse B, Ba F, Sokhna C, Herve JP, Boulanger D, Simondon F: Evaluation of the antibody response to Anopheles salivary antigens as a potential marker of risk of malaria. Trans R Soc Trop Med Hyg 2006, 100:363-370.

33. Waitayakul A, Somsri S, Sattabongkot J, Looareesuwan S, Cui L, Udomsangpetch $R$ : Natural human humoral response to salivary gland proteins of Anopheles mosquitoes in Thailand. Acta Trop 2006, 98:66-73.

34. Andrade BB, Rocha BC, Reis-Filho A, Camargo LM, Tadei WP, Moreira LA, Barral A, Barral-Netto M: Anti-Anopheles darling saliva antibodies as marker of Plasmodium viva infection and clinical immunity in the Brazilian Amazon. Malar J 2009, 8:121.

35. Drame PM, Poinsignon A, Besnard P, Cornelie S, Le Mire J, Toto JC, Foumane V, Dos-Santos MA, Sembene M, Fortes F, Simondon F, Carnevale P, Remoue F: Human antibody responses to the Anopheles salivary gSG6-P1 peptide: a novel tool for evaluating the efficacy of ITNs in malaria vector control. PLoS One 2010, 5:e15596.

36. Poinsignon $A$, Cornelie $S$, Mestres-Simon $M$, Lanfrancotti $A$, Rossignol $M$, Boulanger D, Cisse B, Sokhna C, Arca B, Simondon F, Remoue F: Novel peptide marker corresponding to salivary protein gSG6 potentially identifies exposure to Anopheles bites. PLOS One 2008, 3:e2472.

37. Poinsignon A, Samb B, Doucoure S, Drame PM, Sarr JB, Sow C, Cornelie S, Maiga S, Thiam C, Rogerie F, Guindo S, Hermann E, Simondon F, Dia I, Riveau G, Konate L, Remoue F: First attempt to validate the gSG6-P1 salivary peptide as an immuno-epidemiological tool for evaluating human exposure to Anopheles funestu bites. Trop Med Int Health 2010 15:1198-1203.

38. (SNMS) SNMS: Annual rainfalls in Senegal in 2008.[http://wwwmeteosenegalnet/2009].

39. Gillies MT, Coetzee M: A supplement to the anophelinae of Africa south of the Sahara (Afrotropical region) The South African Institut for Medical Research No. 55 Johannesburg, South Africa; 1987.

40. Robert V, Boudin C: Biology of man-mosquito Plasmodium transmission. Bull Soc Pathol Exot 2003, 96:6-20

41. Geissbuhler Y, Chaki P, Emidi B, Govella NJ, Shirima R, Mayagaya V, Mtasiwa D, Mshinda H, Fillinger U, Lindsay SW, Kannady K, de Castro MC, Tanner M, Killeen GF: Interdependence of domestic malaria prevention measures and mosquito-human interactions in urban Dar es Salaam, Tanzania. Malar J 2007, 6:126.

42. Dambach P, Sie A, Lacaux JP, Vignolles C, Machault V, Sauerborn R: Using high spatial resolution remote sensing for risk mapping of malaria occurrence in the Nouna district, Burkina Faso. Glob Health Action 2009 [http://www.globalhealthaction.net/index.php/gha/article/view/2094/2578]

43. Matthys B, N'Goran EK, Kone M, Koudou BG, Vounatsou P, Cisse G, Tschannen $A B$, Tanner $M$, Utzinger J: Urban agricultural land use and characterization of mosquito larval habitats in a medium-sized town of Cote d'Ivoire. J Vector Ecol 2006, 31:319-333.

44. Afrane YA, Klinkenberg E, Drechsel P, Owusu-Daaku K, Garms R, Kruppa T: Does irrigated urban agriculture influence the transmission of malaria in the city of Kumasi, Ghana? Acta Trop 2004, 89:125-134.

45. Holt RA, Subramanian GM, Halpern A, Sutton GG, Charlab R, Nusskern DR, Wincker P, Clark AG, Ribeiro JM, Wides R, Salzberg SL, Loftus B, Yandell M, Majoros WH, Rusch DB, Lai Z, Kraft CL, Abril JF, Anthouard V, Arensburger P, Atkinson PW, Baden $H$, de Berardinis V, Baldwin D, Benes V, Biedler J, Blass C, Bolanos R, Boscus D, Barnstead M, Cai S, Center A, Chaturverdi K, Christophides GK, Chrystal MA, Clamp M, Cravchik A, Curwen V, Dana A, Delcher A, Dew I, Evans CA, Flanigan M, Grundschober-Freimoser A, Friedli L, Gu Z, Guan P, Guigo R, Hillenmeyer ME, Hladun SL, Hogan JR, Hong YS, Hoover J, Jaillon O, Ke Z, Kodira C, Kokoza E, Koutsos A, Letunic I, Levitsky A, Liang Y, Lin JJ, Lobo NF, Lopez JR, Malek JA, McIntosh TC, Meister S, Miller J, Mobarry C, Mongin E, Murphy SD, O'Brochta DA, Pfannkoch C, Qi R, Regier MA, Remington K, Shao H, Sharakhova MV, Sitter CD, Shetty J, Smith TJ, Strong R, Sun J, Thomasova D, Ton LQ,
Topalis P, Tu Z, Unger MF, Walenz B, Wang A, Wang J, Wang M, Wang X, Woodford KJ, Wortman JR, Wu M, Yao A, Zdobnov EM, Zhang H, Zhao Q, Zhao S, Zhu SC, Zhimulev I, Coluzzi M, della Torre A, Roth CW, Louis C, Kalush F, Mural RJ, Myers EW, Adams MD, Smith HO, Broder S, Gardner MJ, Fraser CM, Birney E, Bork P, Brey PT, Venter JC, Weissenbach J, Kafatos FC, Collins FH, Hoffman SL: The genome sequence of the malaria mosquito Anopheles gambia. Science 2002, 298:129-149.

46. Calvo E, Dao A, Pham VM, Ribeiro JM: An insight into the sialome of Anopheles funestu reveals an emerging pattern in anopheline salivary protein families. Insect Biochem Mol Biol 2007, 37:164-175.

doi:10.1186/1475-2875-11-72

Cite this article as: Drame et al:: IgG responses to the gSG6-P1 salivary peptide for evaluating human exposure to Anopheles bites in urban areas of Dakar region, Sénégal. Malaria Journal 2012 11:72.

\section{Submit your next manuscript to BioMed Central and take full advantage of:}

- Convenient online submission

- Thorough peer review

- No space constraints or color figure charges

- Immediate publication on acceptance

- Inclusion in PubMed, CAS, Scopus and Google Scholar

- Research which is freely available for redistribution

Submit your manuscript at www.biomedcentral.com/submit
Ciomed Central 